\title{
Evaluation of interdecadal trends in sea ice, surface winds and ocean waves in the Arctic in 1980-2019
}

Vitali Sharmar ${ }^{1}$ and Margarita Markina ${ }^{1}$

Received 13 June 2020; accepted 21 September 2020; published 19 March 2021.

Sea ice loss in the Arctic region is one of the well documented consequences of climate change that also affects local atmospheric dynamics and wind-driven surface gravity waves. In this study, we perform the comparative assessment of linear trends in mean and extreme characteristics of $10-\mathrm{m}$ winds and sea ice concentrations from ERA5, ERA-Interim, MERRA2 and NCEP CFSR reanalyses as well as significant wave heights from wind wave hindcasts performed with the spectral wave model WAVEWATCH III forced by these reanalyses in 1980-2019. The largest decline in sea ice concentration in all four reanalyses is observed in autumn and summer in the Chukchi and Beaufort Seas. In winter, all reanalyses and hindcasts agree on positive trends in both 10-m winds and wave heights in the Bering, Okhotsk and Labrador Seas. In spring, all datasets show negative trends in extreme wave heights in the North Pacific Ocean and positive trends in mean winds and wave heights in the western North Atlantic. In summer, positive trends in extreme 10-m winds and wave heights are observed in the Northeast Atlantic, and positive trends in extreme wave heights are revealed in the Sea of Okhotsk. In autumn, positive trends in both mean and extreme winds are observed in the Chukchi and Beaufort Seas as well as along the western coast of Greenland, which coincides with areas with the largest decline in sea ice concentrations. Positive trends in wind speed and wave heights in the Bering Seas are also revealed in all datasets. KEYWORDS: Ice retreat; wave-ice interaction; wind; trends; Arctic.

Citation: Sharmar, Vitali and Margarita Markina (2021), Evaluation of interdecadal trends in sea ice, surface winds and ocean waves in the Arctic in 1980-2019, Russ. J. Earth. Sci., 21, ES2002, doi:10.2205/2020ES000741.

\section{Introduction}

One of the most important consequences of climate change in the Arctic region is a decrease in the sea ice extent and thickness over the past few decades [Collins et al., 2013]. Observations from the modern satellite data showed that sea ice extent exhibits downward linear trends in all months, and particularly in September, while the magni-

\footnotetext{
${ }^{1}$ Shirshov Institute of Oceanology RAS, Moscow, Russia

Copyright 2021 by the Geophysical Center RAS. http://rjes.wdcb.ru/doi/2020ES000741-res.html
}

tude of these trends appears to increase with time [Stroeve et al., 2012. Sea ice loss likely causes the Arctic amplification which is an enhanced warming of the Arctic relative to the other regions detected in both observations and model simulations [Dai et al., 2019]. Local effects on the thermodynamic structure of the atmospheric boundary layer resulting from sea ice loss include changes in atmospheric stability, surface roughness, and baroclinicity. Numerous studies have shown that the number of cyclones entering the Arctic, as well as their intensity, increased in the second half of the 20th century [Trigo, 2006, Zhang et al., 2004. Kudryavtsev et al. 2019 showed that frequency of occurrence of polar lows on the western edge of the 
Barents Sea near the coast of Norway leads to increase in extreme wind wave heights in this region. Furthermore, intensification of cyclones together with extreme wind wave conditions can maintain strong storm surges in the Barents Sea closer to Kola Peninsula region, especially in October [Korablina et al., 2017. Apart from local atmospheric conditions, these changes also affect characteristics of the jet stream and weather in the midlatitudes [Blackport et al., 2019, Francis and Vavrus, 2012].

Overall sea ice decay makes ice pack more vulnerable to strong storms that can cause the separation of large fractions of ice, as was the case during the Great Arctic Cyclone of 2012 [Parkinson and Comiso, 2013. Simmonds and Rudeva, 2012. Decline of sea ice extent also leads to the increase of the open water area and provides favorable conditions for the growth of wind-generated ocean wind waves. In turn, wind waves can affect the formation of new ice, breaking ice floes and altering their distribution, thus controlling the spatial extent of marginal ice zone (MIZ) according to Dumont et al. 2011 and Squire 2007. Enhanced sea ice fragmentation is also associated with the formation of leads which reduce surface albedo and increase the amount of incoming solar radiation. With more open water, air-sea heat fluxes also increase providing a positive feedback on lower atmosphere warming [Cavaleri et al., 2012].

A number of studies investigated linear trends in wind speeds and wave heights in the Arctic in the modern climate. Stopa et al. 2016a showed that both merged altimeter dataset and wind wave hindcast based on CFSR reanalysis in 1992-2014 indicate that the reduction of sea ice cover causes increasing wave heights, which result in shifting freezing period during autumn and still has a key role in the wave-ice interactions. Waseda et al. 2018 analyzing ERA-Interim wave reanalysis, showed an increase in extreme significant wave heights in the Laptev and Beaufort Seas in autumn associated with the enhanced occurrence of storms in ice-free waters. Meucci et al. 2020 demonstrated that ERA20CM, ERA20C and CERA20C show statistically significant positive trends in mean $10-\mathrm{m}$ wind speed up to $1.5 \%$ per decade in the Arctic region during the 20th century (1901-2010). Moreover, these trends are also significant in certain areas of the Chukchi, Barents and Greenland Seas in modern climate (1985-2010). According to studies of Dobrynin et al. 2012, Khon et al. 2014, CasasPrat et al. 2018 the wind wave heights will continue to increase in the Arctic in the future cli- mate which results primarily from simultaneous increase of the open water coverage and increased fetch, as well as with an increase in wind speeds. Mokhov et al. 2007] suggested that navigation season along the Northern Seas Route will be extended by the end of 21-st century according to future climate simulation based on ECHAM5/MPI-OM model under anthropogenic scenario SRES-A2.

Here we investigate the consistency in linear trends in sea ice concentration (SIC), 10-m wind speed and significant wave heights in the Arctic region in 1980-2019. We use information about sea ice and wind conditions from the four modern reanalyses (ERA5, CFSR, ERA-Interim and MERRA-2) and significant wave heights from wind wave hindcasts [Sharmar et al., 2021] based on WAVEWATCH III model forced by 10-m winds from these reanalyses.

\section{Data and Methods}

We use ERA5 [Hersbach et al., 2020] and ERAInterim [Dee et al., 2011] which have been developed by the European Centre for Medium-range Weather Forecasts (ECMWF). ERA5 is a recently released high-resolution dataset (31 km grid spacing) which assimilates a large amount of observational data and replaces ERA-Interim (spatial resolution is $79 \mathrm{~km}$ ), which has been widely used in many contemporary wave analyses. NCEP CFSR is developed by the National Centers of Environmental Prediction (NCEP) and has a spatial resolution of $0.312^{\circ}(1979-2010)$ with a higher resolution $\left(0.205^{\circ}\right)$ in its extension CFSv2 (2011-present time). This reanalysis is also widely used for wave climate studies [Reistard et al., 2011. Stopa et al., 2016b. MERRA2 reanalysis [Gelaro et al., 2017] is developed by the National Aeronautics and Space Administration (NASA) and uses an advanced scheme for winds interpolation from the lowest model level to 10-m height [Helfand and Schubert, 1995 Molod et al., 2015 which is important for the ocean surface wave climate. MERRA2 has spatial resolution of $0.5^{\circ}$ (latitude) $\times 0.625^{\circ}$ (longitude) All four reanalyses assimilate sea ice concentrations from combined SSMR, SSM/I, SSMIS satellite multichannel passive-microwave records [Fennig et al., 2020, Mc Carty et al., 2016. Comparative assessment performed by Lindsay et al. 2014 showed that CFSR, MERRA and ERA-Interim are 

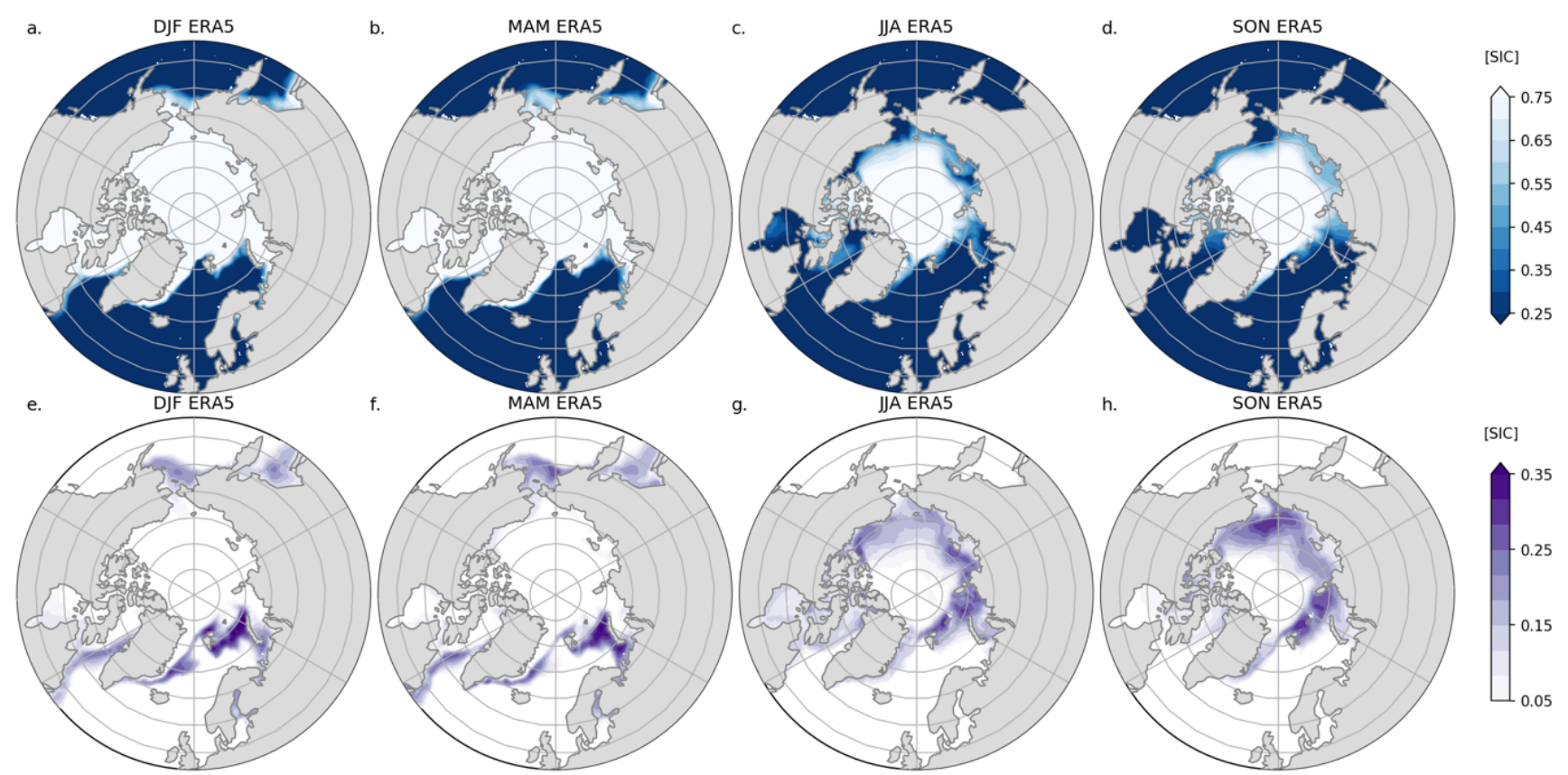

Figure 1. Mean sea ice concentration (a, b, c, d) and its standard deviation (e, f, g, h) in ERA5 in December-February (a, e), March-May (b, f), June-August (c, g) and September-November (d, h) in 1980-2019.

highly consistent with independent observations in reproducing the characteristics of the atmospheric boundary layer in the Arctic.

These reanalyses were used for developing four wind wave hindcasts using version 5.16 of WAVEWATCH III (WW3) spectral wave model [WW3DG, 2016] with source term function ST4 [Ardhuin et al., 2010 and with default settings of wind-wave growth parameter for the period from 1980-2019. Each experiment was run on the grid corresponding to spatial resolution of reanalysis and forced by $10-\mathrm{m}$ winds from these reanalyses. The ice source term package ( $\mathrm{IC} 0$, that considers ice coverage as zero) formulated by [Tolman, 2003 and used in our configuration assumes the exponential attenuation of waves in partially sea ice-covered regions given by 6 -hourly SICs from the corresponding reanalyses. All four hindcasts are found to be in a good agreement with NDBC buoys and satellite data and can be all used for assessment of modern wave climate [Sharmar and Markina, 2020].

\section{Results}

Figure 1 shows mean sea ice concentration (SIC) from ERA5 reanalyses and its standard deviation in different seasons. In all seasons, the largest variability of sea ice concentrations is associated with the areas close to the sea ice boundaries. The highest variability in winter and spring $($ Figure 1, Figure 1:) is observed in the northern Barents Sea, while in summer months there are also high standard deviations of sea ice concentration in the Canadian Arctic as well as in Kara and Laptev Seas. In autumn, high magnitudes of standard deviations in sea ice concentrations are observed in the Chukchi Sea.

Decline in Arctic sea ice extent in all months of the year with the strongest reduction in September is considered to be a very high confidence projection according to IPCC report [Meredith et al., 2019. Figure 2 shows linear trends in sea ice concentration in different seasons as revealed from all four reanalyses. The strongest negative trends are observed in autumn (Figure 2 $\mathrm{d}, \mathrm{h}, \mathrm{l}, \mathrm{p})$, where all datasets agree on the trend sign, particularly in the eastern part of Russian Arctic, and in the western part of Canadian and American Arctic as well as in the Chukchi and Beaufort Seas, where magnitude of trends amount to -0.2 units of SIC decade ${ }^{-1}$. There are also negative trends in the East Siberian, Laptev and Kara Seas. In winter, there is an area with negative trends in the northern Barents Sea (up to -0.15 units of SIC decade $^{-1}$ ) and along the northeastern coast of Greenland, as well as in 


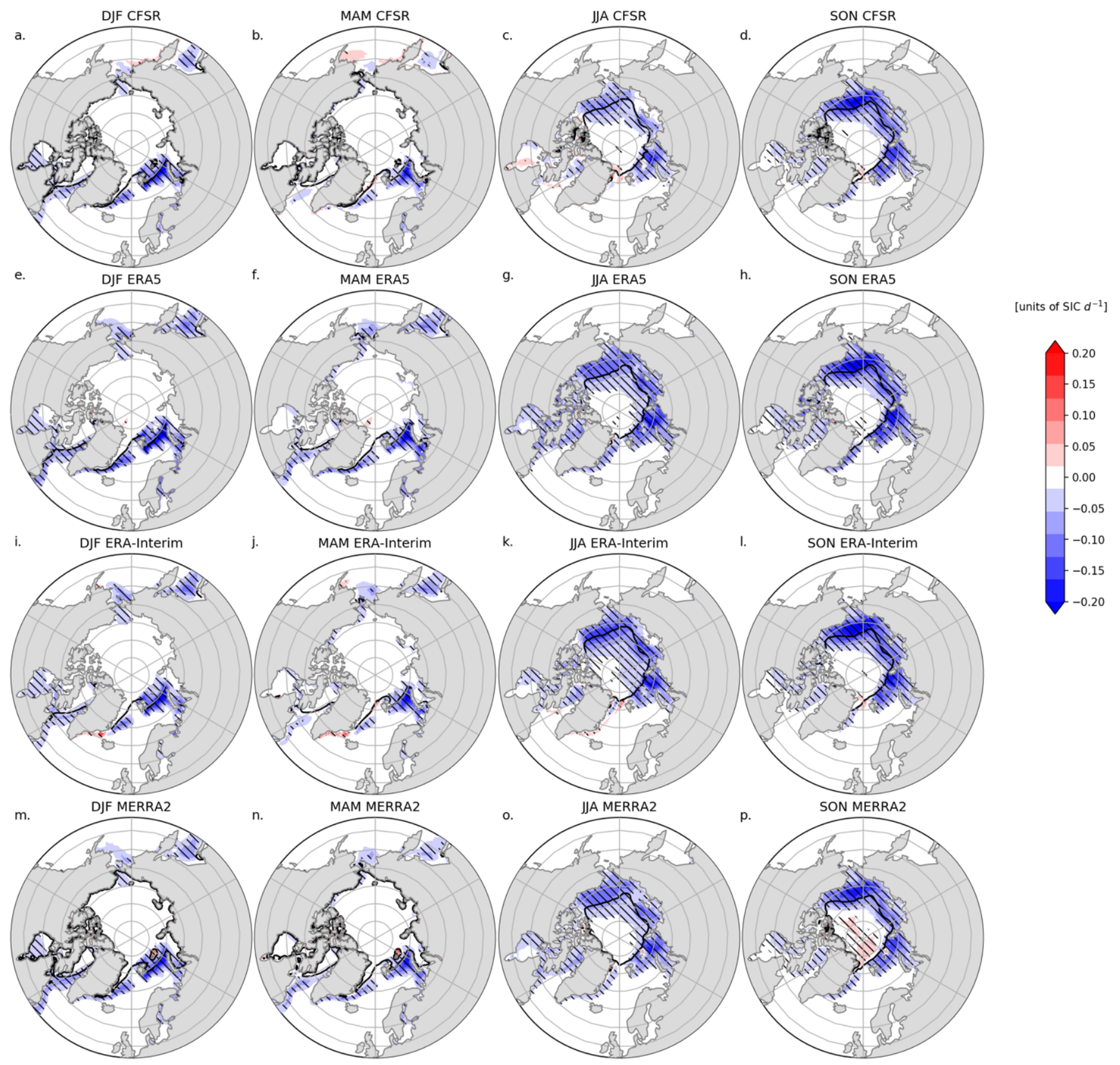

Figure 2. Linear trends in sea ice concentration in 1980-2019 in CFSR (a, b, c, d), ERA5 (e, f, g, h), ERA-Interim (i, j, k, l) and MERRA2 (m, n, o, p) reanalyses in winter (December-February; a, e, i, m), spring (March-May; b, f, j, n), summer (June-August; $\mathrm{c}, \mathrm{g}, \mathrm{k}, \mathrm{o})$ and autumn (SON; d, h, l, p). 

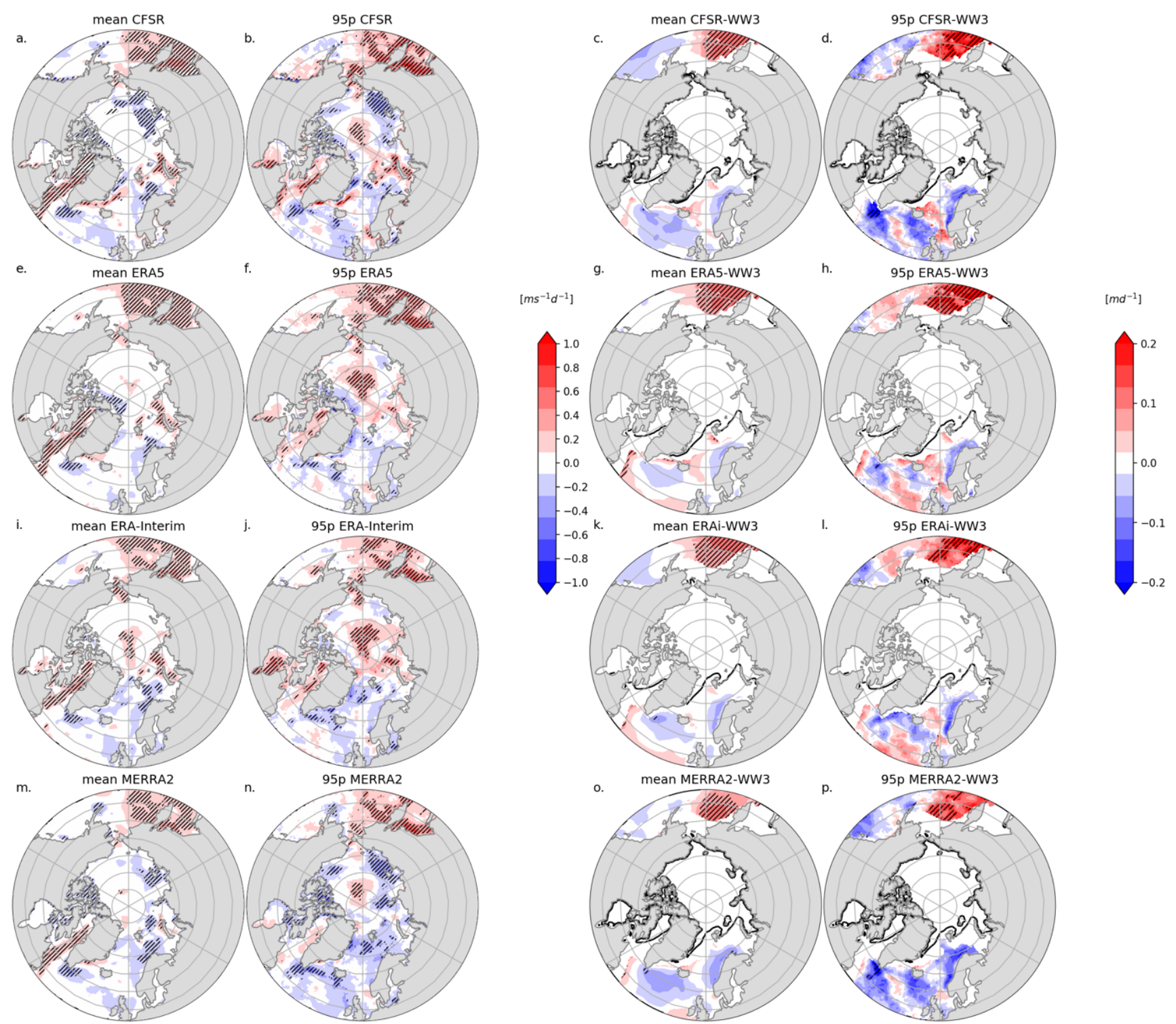

Figure 3. Linear trends in mean (a, c, e, g, i, k, m, o) and 95th percentile (b, d, f, h, j, l, n, p) 10-m winds (a, b, e, f, i, j, m, n) and significant wave heights (c, d, g, h, k, l, o, p) from CFSR (a, b), ERA5 (e, f), ERA-Interim (i, j) and MERRA2 ( $m, n)$ reanalyses and CFSR-WW3 (c, d), ERA5-WW3 (g, h), ERAi-WW3 (k, l) and MERRA2-WW3 (o, p) hindcasts respectively in winter (December-February) in 1980-2019. Black line indicates areas where mean sea ice concentration is greater than $50 \%$ in all years. Lining shows areas where linear trends are significant on the $90 \%$ level according to Student's t-test. 
Laptev Sea and the Sea of Okhotsk (Figure 2a, e, i, $\mathrm{m})$. In spring, there are negative trends along the east coast of Greenland, the Labrador and northeastern Barents Seas and the Sea of Okhotsk (Figure $2 \mathrm{~b}, \mathrm{f}, \mathrm{j}, \mathrm{n}$ ). Trends in summer are similar to the ones observed in autumn, and all reanalyses consistently show the largest trends in the Kara Sea (up to -0.2 units of SIC decade ${ }^{-1}$ in ERA5). Negative trends in the Chukchi and Beaufort Seas are the strongest in Era-Interim (up to -0.2 units of SIC decade $^{-1}$ ) (Figure 2k).

Consistently with the decline in sea ice concentration, positive trends in both mean and extreme 10-m wind speed are observed in all reanalyses in the Sea of Okhotsk as well as in the Bering and Labrador Seas and Baffin Bay (Figure 3 3 , e, i, m). In addition, all datasets show an area with statistically significant positive trends in extreme winds in the Bering and Okhotsk Seas as well as in the central Arctic around the North Pole. MERRA2 and CFSR also show area of negative trends in extreme winds in the East Siberian Sea (Figure 3b, n). All hindcasts show positive trends in the significant wave heights in the Bering Sea (up to 0.1 $\mathrm{m}$ decade $^{-1}$ in means and $0.2 \mathrm{~m}$ decade $^{-1}$ in extremes), while other trends are not statistically significant (Figure 3k, d, g, h, k, l, o, p).

In spring, ERA 5 and CFSR show significant positive trends in both mean and extreme $10-\mathrm{m}$ winds in the western North Atlantic, northeastern Barents Sea and along the southeastern coast of Greenland (Figure 3 a, b, e, f, i, j, m, n). MERRA2 and CFSR show negative trends in both mean and extreme winds in the central Arctic, Laptev, East Siberian and Bering Seas, while in the other reanalyses these trends are not statistically significant. CFSR and ERA5 also show positive trends in mean and extreme winds co-located with the areas of the strong decline of sea ice concentration (Figure 2 b, f). All wind wave hindcasts show negative trends in both mean and extreme wave heights in the Bering Sea and North Pacific Ocean, however in CFSR-WW3 trends have the highest magnitudes $\left(-0.1 \mathrm{~m}\right.$ decade $^{-1}$ in means and $-0.2 \mathrm{~m}$ decade $^{-1}$ in extremes). All hindcasts also show positive trends in mean wave heights in the western and central North Atlantic, and all datasets except ERAi-WW3 also show positive trends in mean and extreme wave heights along the southeastern Greenland coast (Figure 4k, g, k, o).
In summer, all reanalyses agree on the positive trends in extreme $10-\mathrm{m}$ winds in the Northeast Atlantic with the magnitude of up to $0.2 \mathrm{~ms}^{-1}$ decade $^{-1}$ (Figure 3b, f, j, n). ERA5 and CFSR demonstrate large areas with positive trends in both mean and extreme winds in the Beaufort, Chukchi, Kara and Barents Seas with the magnitudes up to $0.6 \mathrm{~ms}^{-1}$ decade $^{-1}$. All hindcasts show negative trends in mean significant wave heights in the Bering Sea and North Pacific, while in CFSRWW3 area with such trends has the largest extent. All hindcasts also agree on the positive trends in extreme wave heights in the Northeast Atlantic (Figure $5 \mathrm{~d}, \mathrm{~h}, \mathrm{l}, \mathrm{p}$ ), while there is a disagreement on the trends in mean wave heights in this region.

In autumn, (Figure 6) all reanalyses show primarily statistically significant positive trends in both mean and extreme 10-m winds in the Bering, Chukchi and East Siberian Seas as well as along the western coast of Greenland. The largest magnitudes of these trends are observed in CFSR (up to $0.6 \mathrm{~ms}^{-1}$ decade $^{-1}$ in means and $1 \mathrm{~ms}^{-1}$ decade $^{-1}$ in extremes). Negative trends in both mean and extreme 10-m winds are observed to the north from Canadian Arctic Archipelago, in Hudson Bay and in the western Barents Sea (Figure 6a, b, e, f, i, j, $\mathrm{m}, \mathrm{n})$.

All wind wave hindcasts show positive trends in the significant wave heights in the Bering Sea (up to $0.15 \mathrm{~m}^{\text {decade }}{ }^{-1}$ in means and greater than $0.2 \mathrm{~m}$ decade $^{-1}$ in extremes). All hindcasts also detect te area of positive trends in mean significant wave heights (up to $0.1 \mathrm{~m}$ decade $^{-1}$ ) in the area southwest from Greenland. MERRA2 and CFSR also show negative trends in extremes along the Scandinavian peninsula (up to $-0.2 \mathrm{~m} \mathrm{decade}^{-1}$ in extremes).

\section{Conclusions}

We evaluated seasonal trends of sea ice concentration, $10-\mathrm{m}$ winds and significant wave heights in the four modern atmospheric reanalyses ERA5, ERA-Interim, NCEP CFSR and MERRA2 and wind wave hindcasts, based on WAVEWATCH III spectral wave model, using information about sea ice and forced by surface winds from these reanalyses. 

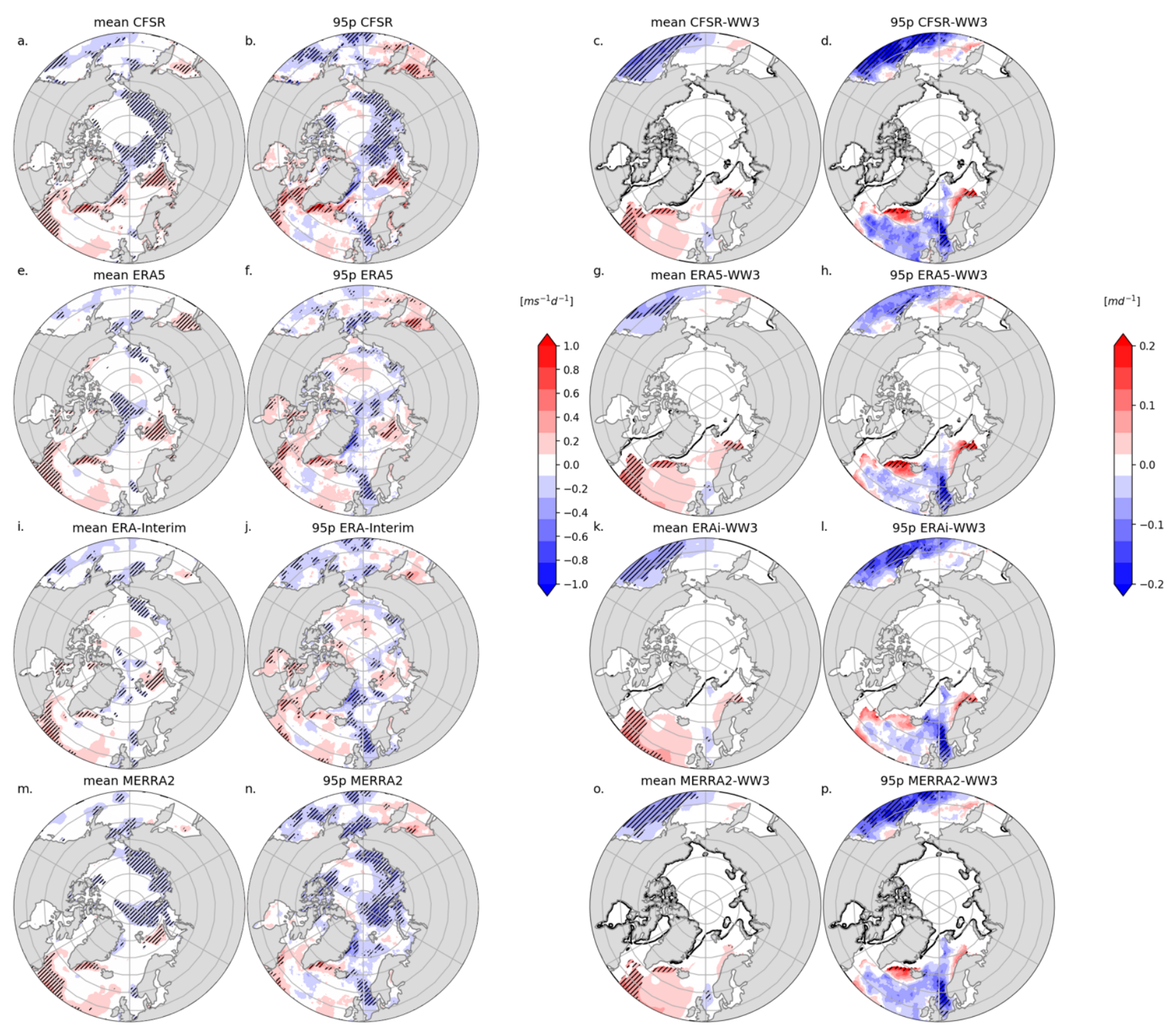

Figure 4. The same as Figure 3 , but for spring (March-May) in 1980-2019.

All reanalyses are in agreement regarding estimates of linear trends in sea ice concentration, and the largest decline in all reanalyses is observed in autumn (September-November) and summer (June-August) in the Chukchi and Beaufort Seas (up to -0.2 units of SIC decade $^{-1}$ ), reflecting a shift towards longer ice-free season in the Arctic in modern climate. In winter and spring, the areas with the largest sea ice decline include the Barents Sea, western coast of Greenland and the Sea of Okhotsk.

In winter, all reanalyses and hindcasts agree on the positive trends in both $10-\mathrm{m}$ winds and wave heights in the Bering and Okhotsk Seas, and on positive trends along the western coast of Greenland. These patterns are co-located with the areas of the large decline in sea ice concentrations. In spring, all hindcasts show negative trends in extreme wave heights in the Bering Sea and North Pacific Ocean. There are also positive trends in mean winds and wave heights in the western North Atlantic. MERRA2 and CFSR show negative trends in wind speed in the seas of Russian Arctic which are not supported by other reanalyses. In summer, positive trends in extreme $10-\mathrm{m}$ winds and wave heights are observed in the Northeast At- 

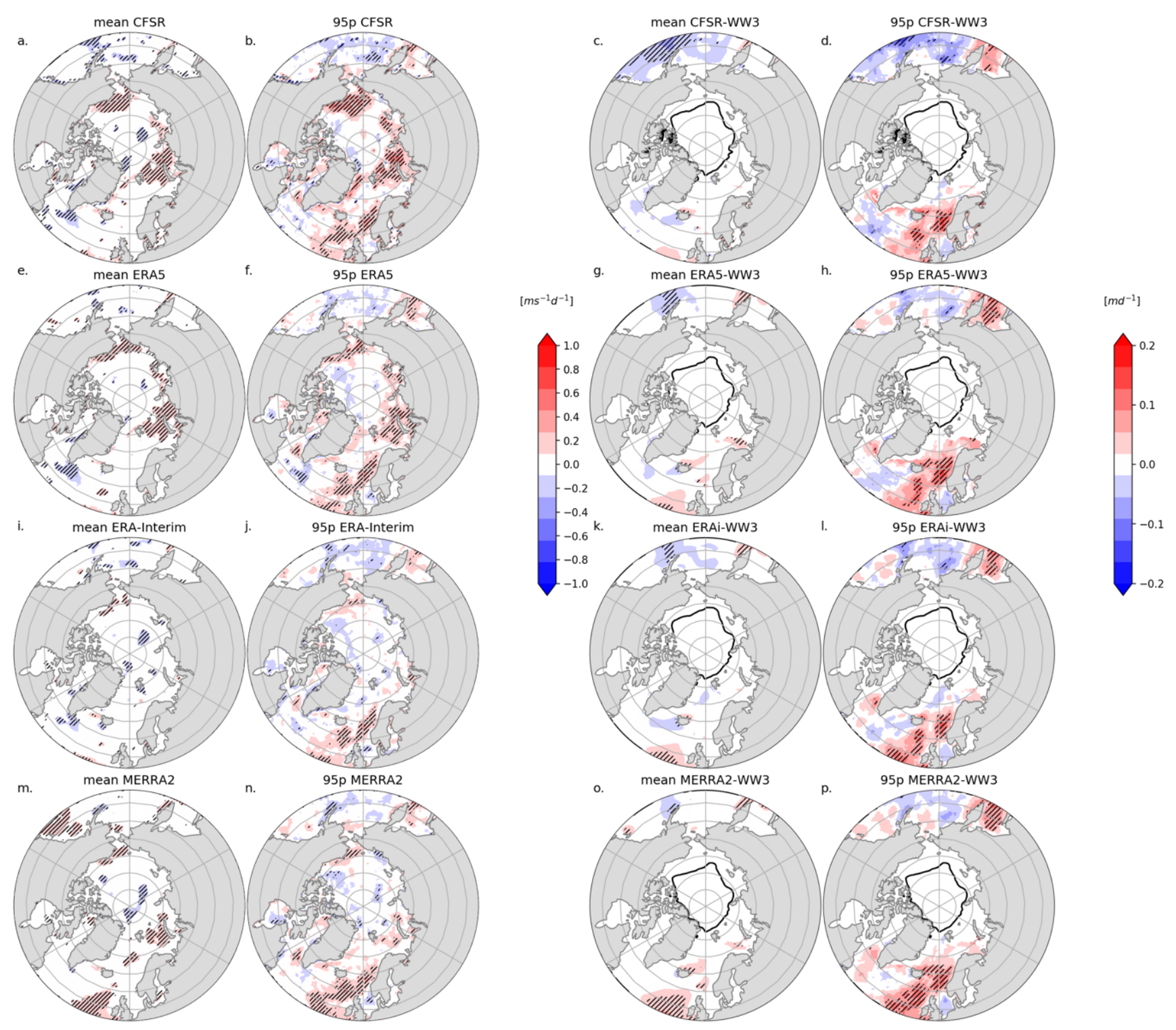

Figure 5. The same as Figure 3, but for summer (June-August) in 1980-2019.

lantic, and there are also positive trends in extreme wave heights in the Sea of Okhotsk. Spatial distribution of trends in autumn shows similar patterns with the one for winter, with positive trends in both mean and extreme winds in the Chukchi and Beaufort Seas as well as along the western coast of Greenland, which coincides with areas with the largest decline in sea ice concentrations. Overall, there are positive trends in wind speed in the Bering Seas in all reanalyses, however, the spatial distribution of statistically significant trends is different. In autumn, there are also positive trends in mean and extreme wave heights in the Bering Sea and along the western coast of Greenland.

This work is a part of ongoing project investigating the mechanisms of response of the wave-iceatmosphere system to changing climate, which final aim is to move towards better understanding and improvement of climate projections in the high latitudes in the 21 st century.

Acknowledgments. This research was supported by the Russian Ministry of Science and Higher Education (grant 05.613.21.0090 project ID RFMEFI61319X0090). 

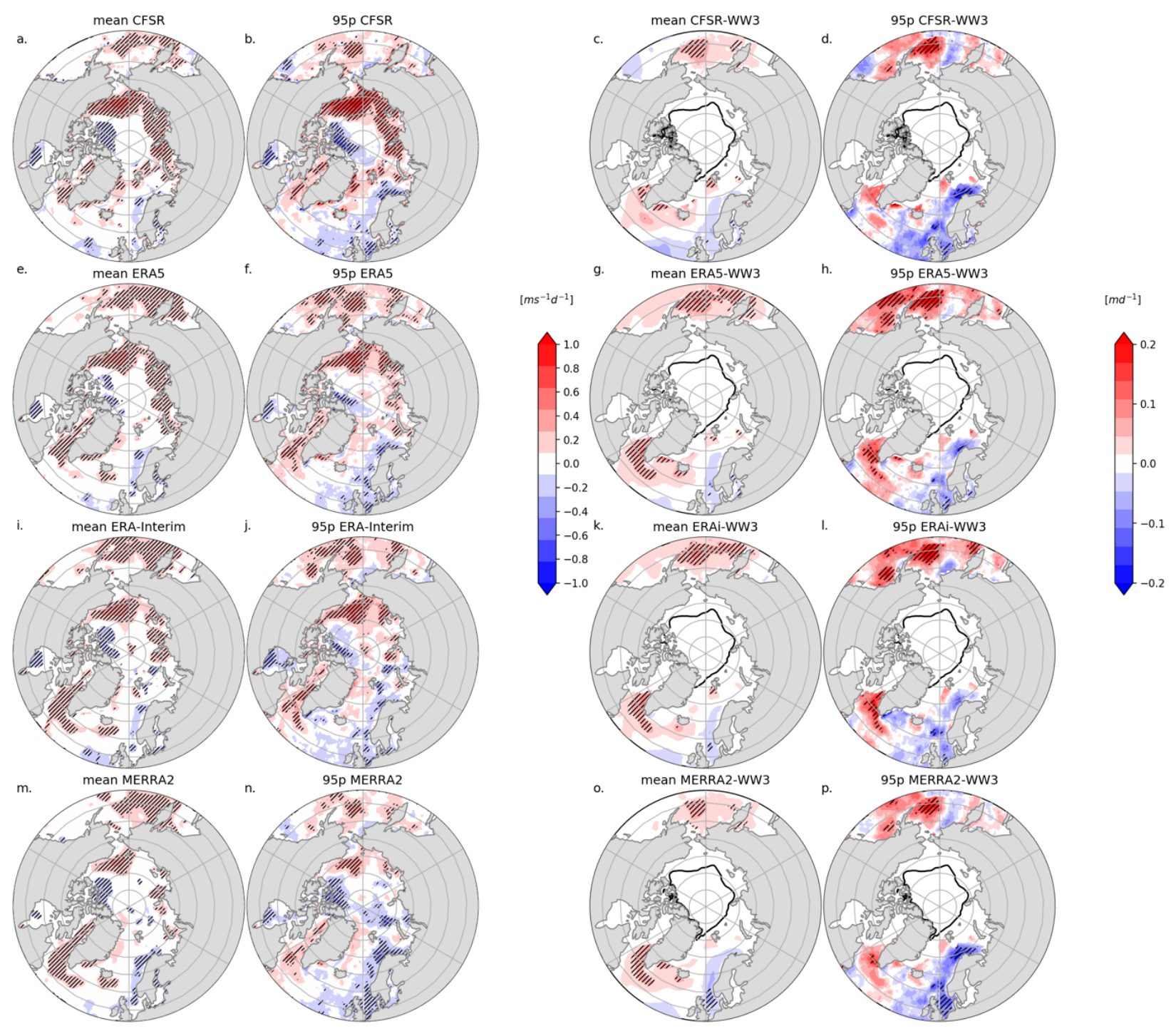

Figure 6. The same as Figure 3, but for autumn (September-November) in 1980-2019.

\section{References}

Ardhuin, F., W. E. Rogers, A. V. Babanin, et al. (2010), Semiempirical dissipation source functions for ocean waves. Part I: Definition, calibration, and validation, J. Phys. Oceanogr., 40, No. 1, 1,9171,941, Crossref

Blackport, R., J. A. Screen, K. van der Wiel, et al. (2019), Minimal influence of reduced Arctic sea ice on coincident cold winters in mid-latitudes, Nat. Clim. Chang., 9, 697-704, Crossref

Casas-Prat, M., X. L. Wang, N. Swart (2018), CMIP5-based global wave climate projections including the entire Arctic Ocean, Ocean Modelling, 123, 66-85, Crossref

Cavaleri, L., B. Fox-Kemper, M. Hemer (2012), Wind waves in the coupled climate system, Bull. Amer. Meteor. Soc., 93, 1651-1661, Crossref
Collins, M., et al. (2013), Long-term climate change: Projections, commitments and irreversibility, Climate Change 2013: The Physical Science Basis, T. F. Stocker et al. (Eds.) p. 1029-1136, University Press, Cambridge.

Dai, A., D. Luo, M. Song, et al. (2019), Arctic amplification is caused by sea-ice loss under increasing $\mathrm{CO}_{2}$, Nat. Commun., 10, 121, Crossref

Dee, D. P., et al. (2011), The ERA-Interim reanalysis: Configuration and performance of the data assimilation system, Quart. J. Roy. Meteor. Soc., 137, 553-597.

Dobrynin, M., J. Murawsky, S. Yang (2012), Evolution of the global wind wave climate in CMIP5 experiments, Geophys. Res. Lett., 39, L18606, Crossref

Dumont, D., A. Kohout, L. Bertino (2011), A wave-based model for the marginal ice zone in- 
cluding a floe breaking parameterization, J. Geophys. Res., 116, C04001, Crossref

Fennig, K., M. Schröder, et al. (2020), Fundamental Climate Data Record of SMMR, SSM/I, and SSMIS brightness temperatures, Earth Syst. Sci. Data, 12, 647-681, Crossref

Francis, J. A., S. J. Vavrus (2012), Evidence linking Arctic amplification to extreme weather in mid-latitudes, Geophys. Res. Lett., 39, L06801, Crossref

Gelaro, R., W. McCarty, M. J. Suárez, et al. (2017), The Modern-Era Retrospective Analysis for Research and Applications, Version 2 (MERRA-2), J. Climate, 30, 5419-5454, Crossref

Helfand, H. M., S. D. Schubert (1995), Climatology of the Simulated Great Plains LowLevel Jet and Its Contribution to the Continental Moisture Budget of the United States, J. Climate, 8, 784-806, Crossref

Hersbach, H., B. Bell, P. Berrisford (2020), The ERA5 global reanalysis, Q. J. R. Meteorol. Soc., 146, 1999-2049, Crossref

Khon, V. C., I. I. Mokhov, et al.

(2014),

Wave heights in the 21st century Arctic Ocean simulated with a regional climate model, Geophys. Res. Lett., 41, 2956-2961, Crossref

Korablina, A., A. Kondrin, V. Arkhipkin (2017), Numerical simulations and statistics of surges in the White and Barents seas, Russ. J. Earth Sci., 17, ES4004, Crossref

Kudryavtsev, V., E. Zabolotskikh, B. Chapron (2019), Abnormal Wind Waves in the Arctic: Probability of Occurrence and Spatial Distribution, Russian Meteorology and Hydrology, 44, No. 4, 268-275, Crossref

Lindsay, R., M. Wensnahan, et al. (2014), Evaluation of Seven Different Atmospheric Reanalysis Products in the Arctic, J. Climate, 27, 2588-2606, Crossref

McCarty, W., L. Coy, R. Gelaro, et al. (2016), MERRA-2 input observations: Summary and initial assessment. Technical Report Series on Global Modeling and Data Assimilation, Vol. 46, NASA Tech. Rep. NASA/TM-2016-104606, 61 pp. NASA, US.

Meredith, M., M. Sommerkorn, et al. (2019), Polar Regions, IPCC Special Report on the Ocean and Cryosphere in a Changing Climate, H.-O. Pörtner et al. (eds.) p. 203-320, Cambridge University press, Cambridge. (https://www. ipcc.ch/srocc/chapter/ch apter-3-2/)

Meucci, A., I. R. Young, et al. (2020), Comparison of Wind Speed and Wave Height Trends from Twentieth-Century Models and Satellite Altimeters, J. Climate, 33, 611-624, Crossref Mokhov, I. I., V. C. Khon, E. Roeckner (2007), Variations in the ice cover of the Arctic Basin in the 21st century based on model simulations: Estimates of the perspectives of the Northern Sea Route, Doklady Earth Sciences, 415, No. 1, 759-763, Crossref

Molod, A., L. Takacs, et al. (2015), Development of the GEOS-5 atmospheric general circulation model: evolution from MERRA to MERRA2, Geosci. Model Dev., 8, 1339-1356, Crossref

Parkinson, C. L., J. C. Comiso (2013), On the 2012 record low Arctic sea ice cover: Combined impact of preconditioning and an August storm, Geophysical Research Letters, 40, No. 7, 1356 1361, Crossref

Reistad, M., Ø. Breivik, et al. (2011), A highresolution hindcast of wind and waves for the North Sea, the Norwegian Sea, and the Barents Sea, J. Geophys. Res., 116, C05019, Crossref Sharmar, V., M. Markina (2020), Validation of global wind wave hindcasts using ERA5, MERRA2, ERA-Interim and CFSRv2 reanalyzes, IOP Conference Series: Earth and Environmental Science, 606, 012056, Crossref

Sharmar, V., M. Markina, S. K. Gulev (2021), Global Ocean Wind-Wave Model Hindcasts Forced by Different Reanalyses: A Comparative Assessment, Journal of Geophysical Research: Oceans, 126, No. 1, Crossref

Simmonds, I., I. Rudeva (2012), The great Arctic cyclone of August 2012, Geophysical Research Letters, 39, No. 23, Crossref

Squire, V. A. (2007), Of ocean waves and sea-ice revisited, Cold Reg. Sci. Technol., 49, 110-133, Crossref

Stopa, J. E., F. Ardhuin, F. Girard-Ardhuin (2016a), Wave climate in the Arctic 19922014: seasonality and trends, The Cryosphere, 10, 1605-1629, Crossref

Stopa, J. E., F. Ardhuin, et al.

(2016b),

Comparison and validation of physical wave parameterizations in spectral wave models, Ocean Modell., 103, 2-17, Crossref

Stroeve, J. C., M. C. Serreze, et al. (2012), The Arctic's rapidly shrinking sea ice cover: A research synthesis, Clim. Change, 110, 10051027, Crossref

Tolman, H. L. (2003), Treatment of unresolved islands and ice in wind wave models, Ocean Modell., 5, 219-231, Crossref

Trigo, I. F. (2006), Climatology and inter- 
annual variability of storm-tracks in the EuroAtlantic sector: a comparison between ERA-40 and NCEP/NCAR reanalyses, Clim. Dyn., 26, 127-143, Crossref

Waseda, T., A. Webb, et al. (2018), Correlated Increase of High Ocean Waves and Winds in the Ice-Free Waters of the Arctic Ocean, Sci. Rep., 8, 4489, Crossref

WW3DG (2016), WAVEWATCH III Development Group, User manual and system documentation of WAVEWATCH III $R$ version 5.16.
Tech. Note 329, 326 pp. NOAA/NWS/NCEP/ MMAB, College Park, MD, USA.

Zhang, X., J. E. Walsh, et al. (2004), Climatology and Interannual Variability of Arctic Cyclone Activity: 1948-2002, J. Climate, 17, 2300-2317, Crossref

Corresponding author:

Vitali Sharmar, Shirshov Institute of Oceanology RAS, 36 Nakhimovskiy Prospekt, 117997 Moscow, Russia. (sharmar@sail.msk.ru) 